\title{
Evaluating constructive and typological retrofits in solid masonry historic buildings
}

\author{
S. Alves \& J. J. Sendra \\ Instituto Universitario de Arquitectura y Ciencias de la Construcción, \\ Escuela Técnica Superior de Arquitectura, Universidad de Sevilla, Spain
}

\begin{abstract}
The historic centre of Oporto, Unesco's World Heritage, should not be acknowledged merely as a set of harmonic façades to preserve. National cultural heritage preservation policies tend to interpret it that way, by allowing alterations on its building's interior. On the other hand, energy commitments assumed, lean towards a propensity to encompass these masonry buildings on this challenge. Although energy regulations allow the exclusion of these buildings, some common retrofit strategies are often proposed. The enhancement of the buildings envelope by adding thermal insulation materials on the interior, or the substitution of single glazed window for a double glazed one are clearly efficient on reducing the envelope's U-value. However, given the specificity of these buildings morphology and its constructive system, there is both an architectural and energetic heritage to preserve. This paper aims to establish this sustainable inherent value, by exploring the potential of a non-intrusive retrofit and its influence on the most expressive energy demand in Oporto - the heating loads. Three models of typological retrofits were defined, using as a criterion the most usual ownership of these buildings. Two retrofit strategies were simulated within these models, according to national regulation's methodology: the enhancement of ventilation and the substitution of the single glazed windows for double glazed ones. Analysis of data obtained evidenced the energetic potential of these buildings on its genesis. The enhancement of ventilation showed to be a most expressive measure in order to reduce operating energy for heating.

Keywords: historic centres, masonry buildings, retrofitting, energy eff ciency, glazing, ventilation.
\end{abstract}




\section{Introduction}

This work fits in the conjunction of two nowadays issues, such as the retrofitting of cities historic centres, acknowledged as cultural heritage, and the concept of energy eff ciency, following the path of a global environmental policy of the European Union countries to reduce energy consumption and $\mathrm{CO}_{2}$ emissions to the atmosphere.

The historic centre of Oporto (HCO) is characterized by stone masonry buildings which have been the subject of several studies and interventions in order to enhance its energetic performance and accomplish Energy commitments assumed. However, as denoted in the last World Heritage Centre's Report [1], there is an "urgent need to implement a new urban culture (...), respecting the preexistence of values and the character of the historic city but giving important advantages for the future". The characterisation of these buildings typologies and its constructive system should determine a both conceptual and operative guideline to the definition of new interventions. Traditional building materials and techniques should be preserved when selecting retrofit strategies that must face a complexity of contemporary demands i.e. thermal performance, maintenance, ecological and recyclable materials, waste management and others. Non-intrusive retrofits must be firstly considered and its thermal performance evaluated.

This paper establishes an operative methodology aiming to position these buildings in relation to the Portuguese regulation on building's energy demand, and the limits thereby defined, focusing on the heating loads as the most expressive comfort request in Oporto. According to this city's climate, some authors [2] defend the notion of "real use", which states that no cooling is used and the heating is used at $30 \%$ of its total load. On the other hand, we can determine the heating loads in a permanent regime and then define the hours of use in order to maintain the building below the energy loads limits.

\section{Retrofit strategies}

Nowadays, Europe's approach to the heritage retrofitting of historic centres is associated with sustainability criteria, seeking to incorporate European regulations on building's habitability and energy efficiency. In this context, in Portugal, 3 documents were established in 2006, RSECE [3], SCE [4] and the most operative for this study, the RCCTE [5], which rules the thermal performance of buildings.

Although the buildings located in historic areas are exempt from these regulations, studies were carried out [2, 6], recommending to the HCO buildings some energy retrofit strategies. In the opaque envelope (walls and roofs) it is proposed the adding of thermal insulation in order to approach the heat transfer coefficients (U-value) defined in RCCTE, or even to overcome them. These recommendations can however enhance the loss of heritage values, such as original plaster work. The glazed areas are also the subject of proposals that can reduce both the U-value and the solar factor. These windows interventions are quite opportune, due to its most common state of conservation. 
Besides some key factors acknowledged to determine the influence of daylighting in buildings thermal performance [7, 8] such as the Fenestration Factor ( $\mathrm{FF}=$ window area/room area), the Window Wall Ratio (WWR $=$ glazing area/ external façade area) and the Effective Aperture (EA = WWR x solar factor), it also recognized the importance of ventilation in the hygrothermal performance of buildings. Whereas, in Oporto, the cooling demand is about $10 \%$ of the heating demand, ventilation has a great impact in the winter season and ventilation may be responsible from $30 \%$ up to $50 \%$ of the total heating demand, which leads to a need to minimize the infiltration rates in order to reduce energy consumption [2]. This has been confirmed in for different countries [9-12]. Recent studies [13] confirm that, in the $\mathrm{HCO}$ buildings it is possible to obtain a significant reduction in the heating demand, improving the infiltration rate. Moreover, by measuring the air-tightness in two non-refurbished characteristic buildings, some relations between the infiltration rates and the buildings morphological and typological characteristics were pointed out [14].

In this study, two retrofit strategies are simulated within three typological models of these historic buildings, according to national RCCTE's methodology: the enhancement of ventilation and the substitution of single glazed windows for double glazed ones.

\section{Methodology}

\subsection{Dwelling units definition}

This building has six storeys west oriented $\left(+22^{\circ}\right)$ and six storeys east oriented $\left(+13^{\circ}\right)$, lagged on the ground floor and top floor, due to the different street levels. The ground floor is usually commerce, with a private staircase. The garret is nonhabitable. This study defined three dwelling units (Figure 1), corresponding to three models of typological retrofits, using as a criterion the most usual ownership of these buildings: Dwelling unit A - One residence with five storeys; Dwelling units B - One residence per storey (four dwellings adapting top floor, B.4); Dwelling units $\mathrm{C}-$ One residence per storey and orientation (9 dwellings).

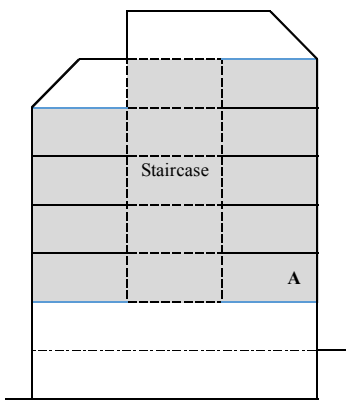

Dwelling Unit A

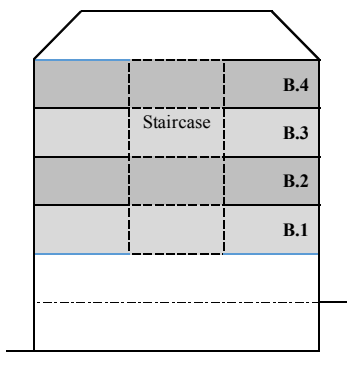

Dwelling Units B

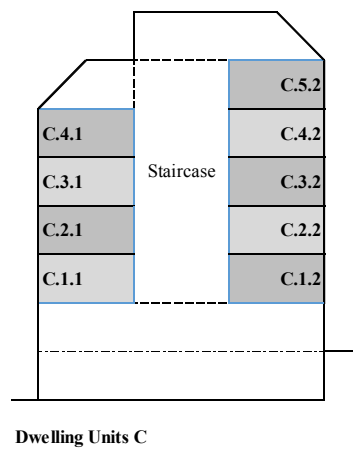

Dwelling Units C

Figure 1: Dwelling units schemes. 
This building has an external envelope of thick stone masonry and, regarding its accountable areas, the internal building envelope is affected by its corresponding coefficient, as described in Table 1. Table 2 specifies the areas and volume of each dwelling unit, while Table 3 presents its constructive materials and corresponding heat transmittance (U-value). The building has a $5 \mathrm{~mm}$ single glazing, within a wooden frame, with internal wooden shutters (U-value $=5.1$ $\left.\mathrm{W} / \mathrm{m}^{2} \mathrm{~K}\right)$.

The RCCTE defines for Oporto a maximum U-value for each element of the external envelope: walls $=0.60 \mathrm{~W} / \mathrm{m}^{2} \mathrm{~K}$; roof $=0.45 \mathrm{~W} / \mathrm{m}^{2} \mathrm{~K}$; windows $=3.30$ $\mathrm{W} / \mathrm{m}^{2} \mathrm{~K}$. It's recognisable that these buildings present values quite distant from those defined in the regulation.

Table 1: Internal envelope's $\tau$ coefficient.

\begin{tabular}{|c|c|}
\hline Type of space & $\tau$ \\
\hline Public staircase & 0.3 \\
\hline Commerce & 0.6 \\
\hline Adjacent buildings & 0.6 \\
\hline Non-habitable garret, lightly ventilated & 0.9 \\
\hline
\end{tabular}

Table 2: Morphological characterisation of the dwelling units.

\begin{tabular}{|c|c|c|c|c|c|c|c|c|c|}
\hline \multirow{2}{*}{$\begin{array}{c}\text { Dwelling } \\
\text { Units }\end{array}$} & Area & Volume & \multicolumn{3}{|c|}{ External Surfaces } & \multicolumn{5}{c|}{ Internal Surfaces } \\
\cline { 2 - 11 } & $\mathrm{m}^{2}$ & $\mathrm{~m}^{3}$ & \multicolumn{3}{|c|}{$\mathrm{m}^{2}$} & \multicolumn{3}{|c|}{$\mathrm{m}^{2}$} \\
\cline { 2 - 11 } & Floor & & Window & Wall & Total & $\tau=\mathbf{0 . 3}$ & $\tau=\mathbf{0 . 6}$ & $\tau=\mathbf{0 . 6}$ & $\tau=\mathbf{0 . 9}$ \\
\hline A & 490.8 & 1572.6 & 67.4 & 107.6 & 175.0 & - & 113.6 & 535.9 & 110.1 \\
\hline B.1 & 113.6 & 369.3 & 15.5 & 20.5 & 36.0 & 46.0 & 113.6 & 124.7 & - \\
B.2 & 109.4 & 372.0 & 15.1 & 27.8 & 42.9 & 50.7 & - & 127.9 & - \\
B.3 & 109.4 & 366.5 & 17.8 & 24.5 & 42.2 & 50.0 & - & 126.0 & - \\
B.4 & 109.4 & 342.4 & 13.8 & 25.6 & 39.4 & 46.7 & - & 117.8 & 109.4 \\
\hline C.1.1 & 57.4 & 186.5 & 10.4 & 10.2 & 20.6 & 20.5 & 57.4 & 58.7 & - \\
C.1.2 & 57.4 & 195.1 & 7.7 & 13.9 & 21.6 & 21.5 & - & 61.4 & - \\
C.1.3 & 57.4 & 192.2 & 10.4 & 10.8 & 21.3 & 21.2 & - & 60.5 & - \\
C.1.4 & 57.4 & 179.6 & 7.7 & 12.1 & 19.9 & 19.8 & - & 56.5 & 57.4 \\
\hline C.2.1 & 53.8 & 174.8 & 5.0 & 10.3 & 15.3 & 20.4 & 53.8 & 55.9 & - \\
C.2.2 & 49.0 & 166.5 & 7.3 & 14.0 & 21.3 & 21.4 & - & 53.6 & - \\
C.2.3 & 49.0 & 164.0 & 7.3 & 13.6 & 21.0 & 21.1 & - & 52.8 & - \\
C.2.4 & 49.0 & 153.2 & 6.1 & 13.5 & 19.6 & 19.7 & - & 49.4 & - \\
C.2.5 & 49.0 & 122.4 & 5.4 & 9.1 & 14.5 & 15.7 & - & 39.4 & 49.0 \\
\hline
\end{tabular}


Table 3: Constructive characterisation and heat transmittance (U-value) of the building's elements.

\begin{tabular}{|l|c|c|c|c|}
\hline & External finish & Structure & Internal finish & $\begin{array}{c}\text { U-value } \\
\left(\mathbf{W} / \mathbf{m}^{2} \mathbf{K}\right)\end{array}$ \\
\hline Façade Wall - W & Lime mortar & Granite $86 \mathrm{~cm}$ & Plaster & 1.87 \\
Façade Wall - E & Lime mortar & Granite $53 \mathrm{~cm}$ & Plaster & 2.39 \\
Roof & Ceramic tile & Wood & Plaster & 2.30 \\
\hline Party Wall & - & Granite $60 \mathrm{~cm}$ & Plaster & 2.01 \\
Floor & - & Wood & Plaster & 1.20 \\
Internal Wall & - & Wood & Plaster & 1.20 \\
\hline
\end{tabular}

\subsection{Simulation schedule}

Two different scenarios were established for the existing building (E). The simulation E.a corresponds to closing the shutters at night, presenting a medium U-value of $5.10 \mathrm{~W} / \mathrm{m}^{2} \mathrm{~K}$. Simulation E.b supposes leaving the shutters open, presenting a medium $\mathrm{U}$-value of $3.40 \mathrm{~W} / \mathrm{m}^{2} \mathrm{~K}$. For the heating demand calculation, RCCTE defines the use of a transparent inner curtain, equivalent to a Solar Factor (g-value) of 0.70 for single colourless glass and 0.63 for double colourless glass.

Three retrofit strategies (R) were defined. The intervention R.1 corresponds to the replacement of single glazing for a double glazed one, which can be done by constructing a new wooden frame following the original design. The intervention R.2 establishes for natural ventilation the regulation's minimum value of 0.60 ACH. The simulation R.3 comprises R.1 and R.2 altogether.

Table 4 presents the different parameters defined and the respective variables affected.

Table 4: Simulation schedule.

\begin{tabular}{|c|c|c|}
\hline \multicolumn{1}{|c}{ ID } & Parameter & Variable \\
\hline \multirow{2}{*}{ E.a } & $\begin{array}{c}\text { Single glazing with internal curtain } \\
\text { Wooden shutters closed by night }\end{array}$ & $\begin{array}{c}\mathrm{g} \text {-value }=0.70 \\
\mathrm{U}=3.40 \mathrm{~W} / \mathrm{m}^{2} \mathrm{~K}\end{array}$ \\
\hline E.b & $\begin{array}{c}\text { Single glazing with internal curtain } \\
\text { Wooden shutters closed by night }\end{array}$ & $\begin{array}{c}\mathrm{g} \text {-value }=0.70 \\
\mathrm{U}=5.10 \mathrm{~W} / \mathrm{m}^{2} \mathrm{~K}\end{array}$ \\
\hline \multirow{2}{*}{ R.1 } & $\begin{array}{c}\text { Double glazing with internal curtain } \\
\text { Wooden shutters closed by night }\end{array}$ & $\begin{array}{c}\mathrm{g} \text {-value }=0.63 \\
\mathrm{U}=2.00 \mathrm{~W} / \mathrm{m}^{2} \mathrm{~K}\end{array}$ \\
\hline R.2 & $\begin{array}{c}\text { Enhancement ventilation } \\
\text { R.1 }\end{array}$ & $0.60 \mathrm{ACH}$ \\
\hline R.3 & R.1 & \\
& R.2 & \\
\hline
\end{tabular}




\subsection{Heating loads calculation}

The Portuguese regulation on the thermal performance of buildings (RCCTE), establishes several parameters to take on account to determine the heating loads of a dwelling unit:

1) Heat losses through building's envelope $\left(Q_{t}\right)$;

2) Heat losses due to air changes $\left(Q_{v}\right)$;

3) Useful heat gains $\left(\mathrm{Q}_{\mathrm{gu}}\right)$, due to lighting, equipment, occupants and solar gains through glazing.

The annual heating demand $\left(\mathrm{N}_{\mathrm{ic}}\right)$ is calculated by eqn. (1).

$$
\mathrm{N}_{\mathrm{ic}}=\left(\mathrm{Q}_{\mathrm{t}}+\mathrm{Q}_{\mathrm{v}}-\mathrm{Q}_{\mathrm{gu}}\right) / \mathrm{A}_{\mathrm{p}}\left(\mathrm{kWh} / \mathrm{m}^{2} \text { year }\right)
$$

In the specific case of these buildings, the heat losses through the external envelope $\left(\mathrm{Q}_{\mathrm{t}}\right)$ don't consider any losses due to thermal bridging once the stone masonry wall is continuous. In this study it is not considered any losses to the terrain, once the ground floor is not heated.

\subsubsection{Climate data}

Oporto city is classified as an "I2" winter climatic zone, corresponding to 6.7 months of heating season and 1610 degree-day (DD) on a $20^{\circ} \mathrm{C}$ basis. The monthly medium value of the medium solar energy incident on a vertical surface south oriented, during the heating season $\left(\mathrm{G}_{\mathrm{Sul}}\right)$ is $93 \mathrm{kWh} /\left(\mathrm{m}^{2} \mathrm{month}\right)$.

\subsubsection{Heat losses through external walls}

During all the heating season, the energy needed to counterbalance these losses is, for each envelope element, calculated by eqn. (2), being: U-value $\left(\mathrm{W} / \mathrm{m}^{2} \mathrm{~K}\right) ; \mathrm{A}-$ internal area of the envelope element $\left(\mathrm{m}^{2}\right)$; DD - degree days (degree-day).

$$
\mathrm{Q}_{\text {ext }}=0.024 \times \mathrm{U} \times \mathrm{A} \times \mathrm{DD}(\mathrm{kWh})
$$

\subsubsection{Heat losses through internal envelope}

According to RCCTE, heat losses through elements of the internal building envelope, eqn. (3), are affected by its corresponding $\tau$ coefficient.

$$
\mathrm{Q}_{\text {lna }}=0.024 \times \mathrm{U} \times \mathrm{A} \times \mathrm{DD} \times \tau(\mathrm{kWh})
$$

\subsubsection{Heat losses due to ventilation}

During the heating season, the energy needed to counterbalance these losses is calculated by eqn. (4), being: $A_{p}-$ floor area $\left(\mathrm{m}^{2}\right) ; \mathrm{P}_{\mathrm{d}}-$ medium height $(\mathrm{m}) ; \mathrm{R}_{\mathrm{ph}}-$ air infiltration rate $\left(\mathrm{h}^{-1}\right)$; DD - degree days (degree-day)

$$
\mathrm{Q}_{\mathrm{v}}=0.024 \times\left(0.34 \times \mathrm{R}_{\mathrm{ph}} \times \mathrm{A}_{\mathrm{p}} \times \mathrm{P}_{\mathrm{d}}\right) \times \mathrm{DD}(\mathrm{kWh} / \text { year })
$$

\subsubsection{Heat gains through glazing}

In the heating season, the solar gains are calculated by eqn. (5), being: $G_{\text {Sul }}-$ monthly medium value of the medium solar energy incident on a vertical surface south oriented, during the heating season $\left(\mathrm{kWh} /\left(\mathrm{m}^{2} \cdot \mathrm{month}\right)\right) ; \mathrm{X}_{\mathrm{j}}-$ orientation 
factor; $F_{h}$ - shading factor due to external obstructions; $F_{o}$ - shading factor due to horizontal elements over the window; $F_{f}$ - shading factor due to vertical elements adjacent to the window; $\mathrm{F}_{\mathrm{g}}$ - window frame factor; $\mathrm{F}_{\mathrm{w}}$ - glazing correction factor (0.90); $\mathrm{g}_{\perp}$ - solar factor; $\mathrm{M}$ - heating season period (months).

$$
Q_{s}=G_{\text {sul }} \sum_{j}\left[X_{j} \times \sum_{n}\left(A \times F_{h} \times F_{o} \times F_{f} \times F_{g} \times F_{w} \times g_{\perp}\right)\right] \times M
$$

\subsubsection{Heating demand limits - $\mathrm{Ni}$}

The dwelling unit cannot exceed an admissible maximum value for the heating energy demand (Ni). This value $\left(\mathrm{kWh} / \mathrm{m}^{2}\right.$.year) depends on the Form Factor (FF) of the dwelling unit and the degree-days (DD) of the local climate, as follows:

$\mathrm{FF} \leq 0.5 \Rightarrow \mathrm{Ni}=4.5+0.0395 \mathrm{DD}$

$0.5<\mathrm{FF} \leq 1 \Rightarrow \mathrm{Ni}=4.5+(0.021+0.037 \mathrm{FF}) \mathrm{DD}$

$1<\mathrm{FF} \leq 1.5 \Rightarrow \mathrm{Ni}=[4.5+(0.021+0.037 \mathrm{FF}) \mathrm{DD}](1.2-0.2 \mathrm{FF})$

$\mathrm{FF}>1.5 \Rightarrow \mathrm{Ni}=4.5+0.06885 \mathrm{DD}$

\subsubsection{Form factor quantification}

The form factor $\left(\mathrm{m}^{-1}\right)$ is the quotient of the sum of the external envelope areas $\left(\mathrm{A}_{\text {ext }}\right)$ and the internal envelope areas $\left(\mathrm{A}_{\text {int }}\right)$ multiplied by its corresponding $\tau$ coefficient, over the internal volume (V), eqn. (6):

$$
F F=\frac{\left(\sum A_{\text {ext }}+\sum A_{\text {int }} \times \tau\right)}{V}
$$

\section{Results and discussion}

Table 5 presents the heating loads $(N i)$ obtained for each dwelling unit and respective simulation for both the existent and retrofitted building. These values were converted in daily hours of heating use, calculated in order to not exceed the limits defined by RCCTE (Table 6).

Considering the existing building, before any constructive retrofit intervention, it is possible to achieve a variable daily heating use, according to each dwelling pattern. The fact of closing the internal wooden shutters by night corresponds to an hour gained in the heating use for all dwellings, except for B.3, gaining $2 \mathrm{~h}$. This floor has a glazing area superior to the other B dwellings. Even with the shutters left open, the hours of heating use go from a minimum of $12 \mathrm{~h}$ in some dwellings with heat losses through the roof or the ground floor, to a maximum of $15 \mathrm{~h}$ in the middle floors and $17 \mathrm{~h}$ on dwelling C.2.5., which has the smaller interior height.

In relation to E.a (shutters closed), the intervention R.1, using double glazing, allows one more hour gained of heating use. On the other hand, the enhancement of ventilation (R.2) corresponds to a gain of $2 \mathrm{~h}$. The conjunction of these two strategies (R.3), permits a heating use from a minimum of $15 \mathrm{~h}$ in dwellings with heat losses through the roof or the ground floor, to a maximum of $22 \mathrm{~h}$ in middle floors and $20 \mathrm{~h}$ in C.2.5. These results are rather superior to the previously referred notion of a real use of $30 \%$ of the heating loads, equivalent to 8 daily hours. 
Table 5: Heating loads.

\begin{tabular}{|c|c|c|c|c|c|c|}
\hline \multirow{2}{*}{$\begin{array}{c}\text { Dwelling } \\
\text { Units }\end{array}$} & $\begin{array}{c}\text { Ni } \\
\left(\mathrm{kWh} / \mathrm{m}^{2} \cdot \text { year }\right)\end{array}$ & \multicolumn{2}{|c|}{ Existent } & \multicolumn{3}{c|}{ Retrofit } \\
\cline { 3 - 7 } A & 68.1 & 113.2 & 122.1 & 106.9 & 99.7 & 93.4 \\
\hline $\mathbf{B . 1}$ & 69.4 & 127.8 & 136.7 & 121.5 & 115.1 & 108.7 \\
$\mathbf{B . 2}$ & 68.1 & 113.3 & 122.3 & 106.9 & 100.0 & 93.6 \\
$\mathbf{B . 3}$ & 68.1 & 112.2 & 122.7 & 104.8 & 94.8 & 87.4 \\
$\mathbf{B . 4}$ & 77.0 & 142.3 & 150.6 & 136.7 & 130.0 & 124.4 \\
\hline $\mathbf{C . 1 . 1}$ & 69.1 & 127.8 & 139.7 & 119.3 & 110.9 & 102.4 \\
$\mathbf{C . 1 . 2}$ & 68.1 & 103.9 & 112.7 & 97.7 & 90.6 & 84.5 \\
$\mathbf{C . 1 . 3}$ & 68.1 & 99.7 & 111.5 & 91.6 & 82.4 & 74.4 \\
$\mathbf{C . 1 . 4}$ & 75.2 & 133.2 & 142.0 & 127.5 & 119.0 & 113.2 \\
\hline $\mathbf{C . 2 . 1}$ & 68.1 & 126.1 & 132.2 & 121.7 & 113.3 & 109.0 \\
$\mathbf{C . 2 . 2}$ & 68.1 & 115.7 & 125.4 & 108.7 & 102.4 & 95.4 \\
$\mathbf{C . 2 . 3}$ & 68.1 & 113.8 & 123.6 & 106.8 & 100.7 & 93.7 \\
$\mathbf{C . 2 . 4}$ & 68.1 & 105.7 & 113.8 & 99.9 & 93.5 & 87.7 \\
$\mathbf{C . 2 . 5}$ & 80.6 & 109.0 & 116.1 & 104.3 & 99.2 & 94.5 \\
\hline
\end{tabular}

Table 6: Daily heating hours.

\begin{tabular}{|c|c|c|c|c|c|}
\hline \multirow{2}{*}{ Dwelling Units } & \multicolumn{2}{|c|}{ Existent } & \multicolumn{3}{c|}{ Retrofit } \\
\cline { 2 - 6 } & E.a & E.b & R.1 & R.2 & R.3 \\
\hline A & 14 & 13 & 15 & 16 & 17 \\
\hline B.1 & 13 & 12 & 14 & 14 & 15 \\
B.2 & 14 & 13 & 15 & 16 & 17 \\
B.3 & 15 & 13 & 16 & 17 & 19 \\
B.4 & 13 & 12 & 14 & 14 & 15 \\
\hline C.1.1 & 13 & 12 & 14 & 15 & 16 \\
C.1.2 & 16 & 15 & 17 & 18 & 19 \\
C.1.3 & 16 & 15 & 18 & 20 & 22 \\
C.1.4 & 14 & 13 & 14 & 15 & 16 \\
\hline C.2.1 & 13 & 12 & 13 & 14 & 15 \\
C.2.2 & 14 & 13 & 15 & 16 & 17 \\
C.2.3 & 14 & 13 & 15 & 16 & 17 \\
C.2.4 & 15 & 14 & 16 & 17 & 19 \\
C.2.5 & 18 & 17 & 19 & 19 & 20 \\
\hline
\end{tabular}

Analysing the data obtained, it is possible to infer that the Fenestration Factor ( $\mathrm{FF}=\mathrm{Window}$ area/room area) and the Window Wall Ratio (WWR = glazing area/ external façade area) are morphological parameters determinant in the hydrothermal performance of the buildings. Table 7 presents the values of these parameters for each dwelling unit and the corresponding energy saving per retrofit strategy. 
Table 7: Energy saving per retrofit strategy.

\begin{tabular}{|c|c|c|c|c|c|c|c|c|}
\hline \multirow{2}{*}{$\begin{array}{c}\text { Dwelling } \\
\text { Units }\end{array}$} & \multicolumn{4}{|c|}{ Area } & \multicolumn{2}{c|}{ Ratio } & \multicolumn{3}{c|}{ Energy Saving to E.a } \\
\cline { 2 - 9 } & $\mathrm{m}^{2}$ & $\mathrm{~m}^{2}$ & $\mathrm{~m}^{2}$ & $\%$ & $\%$ & \multicolumn{3}{c|}{$\left(\mathrm{kWh} / \mathrm{m}^{2}\right.$ year } \\
\cline { 2 - 9 } & Floor & Window & Wall & WWR & FF & R.1 & R.2 & R.3 \\
\hline A & 490.8 & 67.4 & 175.0 & 38.5 & 13.7 & 6.3 & 13.5 & 19.7 \\
\hline B.1 & 113.6 & 15.5 & 36.0 & 43.0 & 13.6 & 6.4 & 12.7 & 19.1 \\
B.2 & 109.4 & 15.1 & 42.9 & 35.1 & 13.8 & 6.4 & 13.3 & 19.7 \\
B.3 & 109.4 & 17.8 & 42.2 & 42.0 & 16.2 & 7.4 & 17.4 & 24.8 \\
B.4 & 109.4 & 13.8 & 39.4 & 35.0 & 12.6 & 5.6 & 12.3 & 17.9 \\
\hline C.1.1 & 57.4 & 10.4 & 20.6 & 50.6 & 18.2 & 8.5 & 17.0 & 25.5 \\
C.1.2 & 57.4 & 7.7 & 21.6 & 35.8 & 13.5 & 6.2 & 13.3 & 19.4 \\
C.1.3 & 57.4 & 10.4 & 21.3 & 49.1 & 18.2 & 8.1 & 17.3 & 25.3 \\
C.1.4 & 57.4 & 7.7 & 19.9 & 39.0 & 13.5 & 5.7 & 14.3 & 20.0 \\
\hline C.2.1 & 53.8 & 5.0 & 15.3 & 32.7 & 9.3 & 4.4 & 12.8 & 17.1 \\
C.2.2 & 49.0 & 7.3 & 21.3 & 34.4 & 15.0 & 7.0 & 13.3 & 20.3 \\
C.2.3 & 49.0 & 7.3 & 21.0 & 34.9 & 15.0 & 7.0 & 13.1 & 20.1 \\
C. 2.4 & 49.0 & 6.1 & 19.6 & 31.0 & 12.4 & 5.8 & 12.2 & 18.0 \\
C.2.5 & 49.0 & 5.4 & 14.5 & 37.0 & 11.0 & 4.7 & 9.8 & 14.5 \\
\hline
\end{tabular}

In order to explore some potential correlation between these factors, two samples were established. One comprises all the dwelling units $(n=14)$ and the other excludes the first and the top floors (B.1, B.4, C.1.1, C.1.4, C.2.1, C.2.5), influenced by heat losses through the ground floor and roof $(n=8)$.

The correlation coefficient (R), measures the strength and direction of the linear relationship between two variables. It is commonly classified as a strong correlation if its value is superior to 0.60 , and a very strong one if its value is superior to 0.80 . Table 8 presents the correlation coefficients obtained between WWR and FF and each retrofit energy saving.

Table 8: Correlation coefficient (R) between WWR, FF and retrofit energy savings.

\begin{tabular}{|c|c|c|c|c|}
\hline \multirow{2}{*}{$\begin{array}{c}\text { Energy } \\
\text { saving }\end{array}$} & \multicolumn{2}{|c|}{$\mathbf{n = 1 4}$} & \multicolumn{2}{c|}{$\mathbf{n = 8}$} \\
\cline { 2 - 5 } & WWR & FF & WWR & FF \\
\hline R.1 & 0.73 & 0.98 & 0.82 & 0.99 \\
\hline R.2 & 0.74 & 0.83 & 0.91 & 0.88 \\
\hline R.3 & 0.77 & 0.93 & 0.92 & 0.94 \\
\hline
\end{tabular}

It is recognisable that the Form Factor has a very strong positive correlation with all the interventions, being obviously more expressive in the implementation of double glazing (R.1), in the two samples. On the other hand, the Window Wall Ratio is slightly more determinant in the enhancement of ventilation (R.2), presenting a very strong positive correlation in sample $n=8$, remaining a strong one in the sample $n=14$. 


\section{Conclusions}

Regarding the results obtained with this study we can conclude that it is possible to obtain a signif cant increase of the energy eff ciency in the buildings of the historic centre of Oporto, when improving the windows infiltration rate. A primary measure to ensure this performance enhancement is to reduce direct drafts from air leakage to minimum values when the building is not occupied, so to avoid superficial humidity from condensation, and enable its gradual increase when occupied, counting on adjustable airflow ventilation systems. One of the key procedures to accomplish this air leakage adjustment is precisely to upgrade the air infiltration rate of the windows framing, avoiding any cracks in the window assembly. Subsequently, it is particularly opportune the replacement of single glazing for a double glazed one, by constructing a new wooden frame following the original design. This intervention contributes to both the thermal and acoustic performance of buildings.

According to the Portuguese regulation on the thermal performance of buildings (RCCTE), although the building's envelope presents heat transmittance values (U) quite distant from the limits thereby defined, its energetic heating demand can be placed below its corresponding limit, in comfortable conditions of heating use.

In addition, the Form Factor and the Window Wall Ratio proved to be morphological characteristics quite determinant in the heating energy savings, within the defined retrofit strategies. These non-intrusive interventions, while no adding any new materials to the external envelope, enhances the architectural heritage values of these buildings by enabling the maintenance of the windows original design and its internal wooden shutters.

\section{References}

[1] WHC, State of Conservation of World Heritage Properties in Europe: Section II, 2006, www.whc.unesco.org/archive/periodicreporting/EUR/ cycle01/section2/755-summary.pdf

[2] SRU (eds). Reabilitação de Edifícios do Centro Histórico do Porto: Guia de Termos de Referência para o Desempenho Energético-Ambiental, SRU: Porto, 2010.

[3] RSECE, Regulamento dos Sistemas Energéticos de Climatização em Edifícios, Decreto-Lei n. ${ }^{\circ}$ 79/ 2006 de 4 de Abril, 2006.

[4] SCE, Sistema Nacional de Certificação Energética e da Qualidade do Ar Interior nos Edifícios, Decreto-Lei n. ${ }^{\circ}$ 78/ 2006 de 4 de Abril, 2006.

[5] RCCTE (2006) Regulamento das Características de Comportamento Térmico de Edifícios, Decreto-Lei n. ${ }^{\circ}$ 80/ 2006 de 4 de Abril, 2006.

[6] OERN (eds). Manual de Apoio ao Projecto de Reabilitação de Edifícios Antigo, OERN: Porto, 2012.

[7] Saridar, S. \& Elkadi, H., The impact of applying recent façade technology on daylighting performance in buildings in eastern Mediterranean. Building and Environment 37, pp. 1205-1212, 2002. 
[8] Freire, R. Z., Mazuroski, W., Abadie, M.O., Mendes, N., Capacitive effect on the heat transfer through building glazing systems. Applied Energy 88, pp. 4310-4319, 2011.

[9] Papadopoulos, A.M., Teodosiou, T.G., Karatzas, K.D., Feasibility of energy saving measures in urban buildings. The impact of energy prices and the acceptable pay back criterion. Energy and Buildings 34, pp. 455-466, 2002.

[10] Tommerup, H., Svendsen, S., Energy savings in Danish residential building stock. Energy and Buildings 38, pp. 618-626, 2006.

[11] Domínguez, S., Sendra, J.J., León, A.L., Esquivas, P.M., Towards an energy demand reduction in social housing buildings: Envelope system optimization strategies. Energies 5, pp. 2263-2287, 2012.

[12] Binamu A., Integrating building design properties "air tightness" and ventilation heat recovery for minimum heating energy consumption in cold climates. Dissertation. Tampere University of Technology, 2002.

[13] Alves, S., Sendra, J.J., Rehabilitation and Energy efficiency Methodological strategies for the Historic Centre of Oporto. Book of proceedings: Heritage 2012 - Heritage and Sustainable Development. Chapter 3 - Heritage and Environment. p. 395. Green Lines Institute, eBook ISBN: 978-989-95671-8-4, 2012.

[14] Alves, S., Fernández-Agüera, J., Sendra, J.J., Infiltration rate performance of buildings in the historic centre of Oporto. Informes de la Construcción 66(535), 2014. 